\title{
Prática da sustentabilidade de uma instituição financeira na Amazônia Legal: um estudo de caso
}

Sustainability practice of a financial institution in the Legal Amazon: a case study

\author{
Filipe Rios Pontes ${ }^{1 *}$, Renata Maria Marè²
}

1*Bacharel em Engenharia de Produção - Rua Carlos Fernandes, 94 - Niterói - 28300-000 - Itaperuna, RJ - Brasil <filiperios_@hotmail.com>

${ }^{2}$ Escola Politécnica da Universidade de São Paulo - Doutoranda em Engenharia de Computação e Sistemas Digitais - Av. Prof. Luciano Gualberto, tv 3 , 158 - Butantã 05508-010 - São Paulo, SP - Brasil

\section{Resumo}

Em meio à atual conjuntura de impactos causados pelo desenvolvimento humano, as empresas devem criar mecanismos e formas de avaliação da sustentabilidade para operacionalizar o conceito de desenvolvimento sustentável. O presente trabalho teve o objetivo de avaliar e analisar a sustentabilidade de uma instituição financeira, atuante na região da Amazônia Legal Brasileira, por meio de um estudo de caso, com a aplicação das metodologias de mensuração da sustentabilidade "Global Reporting Initiative" [GRI] e Método de Avaliação dos Indicadores de Sustentabilidade Organizacional [M.A.I.S.], além de análises documentais. A avaliação da sustentabilidade mostrou que a instituição é sustentável nas dimensões social, econômica e ambiental, mas necessita melhorar nos aspectos referentes à dimensão cultural.

Palavras-chave: desenvolvimento organizacional, desenvolvimento sustentável, mensuração da sustentabilidade

\begin{abstract}
In the current context of impacts caused by human development, companies must create mechanisms and forms of sustainability assessment to operationalize the concept of sustainable development. The present work had the objective of evaluating and analyzing the sustainability of a financial institution, operating in the Brazilian Legal Amazon region, through a case study, applying the Global Reporting Initiative [GRI] (2008) and Method of Evaluation of Organizational Sustainability Indicators M.A.I.S. (2002), as well as documentary analyzes. The sustainability assessment showed that the institution is sustainable in the social, economic and environmental dimensions, but needs to improve in aspects related to the cultural dimension.
\end{abstract}

Keywords: organizational development, sustainable development, sustainability measurement

\section{Introdução}

A atenção e preocupação, em relação às ações e atividades exercidas pelo homem que impactam as dimensões ambientais, sociais e econômicas, têm se tornado maiores a cada dia. Um marco inicial na disseminação da discussão desses impactos, foi o surgimento do conceito de desenvolvimento sustentável. Esse conceito emergiu, pela primeira vez, com o nome de "ecodesenvolvimento", em meados dos anos 1970 (Romeiro, 1999).

De acordo com Silva (2011), alguns anos depois do início desse movimento, o termo "desenvolvimento sustentável" surgiu, mas somente quase uma década depois tomou notoriedade internacional por meio do relatório de "Brundtland", o qual define desenvolvimento sustentável como a capacidade de suprir a geração atual, sem comprometer as gerações futuras (CMMAD, 1988).

Em 1994, Elkington (1994) começou a tentar integrar as dimensões econômica, social e ambiental, apresentando, assim, o termo "win-win-win". De acordo com Elkington (2004) esse conceito foi criado, para que algum progresso ambiental fosse feito por parte das organizações. Em 1995, a evolução desse termo deu origem ao conceito "People, Planet and Profit", que em 1997, através do livro "Cannibals with Forks: The Triple Bottom Line of 21st Century Business" viria a ser chamado de "Triple Bottom Line" (Elkington, 2004). O modelo "Triple Bottom Line" ou tripé da sustentabilidade, além de abranger aspectos econômicos, inclui os sociais e ambientais, todos com iguais pesos para avaliação do desempenho geral da organização (Elkington, 2004).

Nesse contexto, as empresas passaram a ser demandadas, quanto às suas práticas em relação às dimensões da sustentabilidade (Oliveira, 2002) ${ }^{1}$. Não foi diferente para empresas financeiras, que tiveram que se adaptar às constantes pressões da agenda de sustentabilidade e à evolução da legislação (Silva, 2011). Segundo Silva (2011), em relação, às instituições financeiras brasileiras, estas não acompanharam o desdobramento internacional. Somente a partir de 1995, com o lançamento do "Protocolo Verde" e posteriormente, a implementação da Lei de Crimes Ambientais, n. 9.605 de 12 de fevereiro de 1998, é que se iniciaram os compromissos de atuação responsável, por parte dessas instituições (Silva, 2011).

${ }^{1}$ Oliveira, J.H.R. 2002. M.A.I.S: método para avaliação de indicadores de sustentabilidade organizacional. Tese de Doutorado em Engenharia de Produção. Universidade Federal de Santa Catarina, Florianópolis, SC, Brasil. Disponível em: <https://core.ac.uk/download/pdf/30365409.pdf>. Acesso em: 28 mar. 2017.

Recebido: 31 out. 2017

Aprovado: 08 mar. 2018 
Para operacionalizar o conceito de desenvolvimento sustentável, ajudar a identificar questões chave e prover informações sobre a sua contribuição em relação à sustentabilidade, as empresas necessitaram criar ferramentas (indicadores de sustentabilidade) para a avaliação de todos os elementos que compõem o tripé da sustentabilidade, de modo que pudessem mensurar e traduzir os problemas em indicadores quantitativos (Krajnc e Glavič, 2005; Van Bellen, 2006).

Devido ao cenário emergente, às constantes exigências e pressões e à relevấncia que o tema tem ganhado nas esferas empresariais e acadêmicas, $O$ trabalho avaliou as práticas de sustentabilidade em uma instituição financeira brasileira de grande porte, o Banco A, objeto de estudo.

O Banco A tem atuação na região da Amazônia Legal Brasileira, que é composta pelos estados do Acre, Amapá, Amazonas, Mato Grosso, Pará, Rondônia, Roraima, Tocantins e parte do Maranhão. Também foi caracterizado como o principal agente de fomento no norte do país, sendo responsável por mais de $60 \%$ do volume de crédito de estímulo à produção e ao desenvolvimento local. Vários tipos de atividades foram beneficiadas, dentre elas destacaram: comércio, prestação de serviços, setor agropecuário, agricultura familiar, turismo e atividades industriais. Além disso, sua visão, missão e valores foram alinhados para a busca da sustentabilidade, com o objetivo de ser reconhecido como um dos atores de desenvolvimento sustentável na região.

A ampla atuação envolvendo vários setores, o volume de crédito concedido, a postura organizacional em relação à sustentabilidade, e o fato de operar e ter influência no desenvolvimento da região da Amazônia Legal Brasileira, que representa $60 \%$ do território nacional, tornam o Banco A um estudo de caso relevante para a pesquisa.

Por fim, esse artigo teve a finalidade de avaliar e analisar a sustentabilidade organizacional do Banco A, de verificar se as práticas por ele adotadas, em relação à sustentabilidade, ocorreram devido ao amadurecimento da organização ou por obrigatoriedade de implantação, além de verificar se ele contribui ou não para o desenvolvimento sustentável local.

\section{Material e Métodos}

\section{Classificação da pesquisa}

Esse projeto, de acordo com Silva e Menezes (2005), caracterizou-se, em relação à sua natureza, como uma pesquisa aplicada, uma vez que objetivou gerar novos conhecimentos para aplicação prática. Do ponto de vista da forma de abordagem, pode-se caracterizá-la tanto como quantitativa e qualitativa. Quantitativa, pois mensurou a sustentabilidade organizacional de uma instituição financeira, e qualitativa porque objetivou responder a perguntas que não eram quantificáveis, as quais indicaram se a organização estudada era comprometida ou não com a sustentabilidade. O ambiente natural foi a fonte direta de coleta de dados.

Em relação ao tipo da pesquisa, está situada no grupo de pesquisa descritiva, pois visou descrever as relações e características da sustentabilidade na organização proposta (Gil, 2008). Os procedimentos técnicos utilizados foram: pesquisa bibliográfica, pesquisa documental e estudo de caso.

A pesquisa documental e o estudo de caso, apoiadas pela pesquisa bibliográfica, também, serviram de base para responder se a busca da sustentabilidade empresarial, por parte da organização em estudo, ocorreu por amadurecimento da organização ou por obrigatoriedade de implantação de práticas sustentáveis, e se ela contribui para o desenvolvimento sustentável da região. Para isso, de acordo com a classificação proposta por Gil (2008), foram avaliados documentos de primeira mão (documentos oficiais, reportagens de jornal, entre outros) e de segunda mão (relatório de empresas, tabelas estatísticas, entre outros).

\section{Estrutura metodológica da pesquisa}

A pesquisa foi dividida em três etapas, com metodologias específicas aplicadas a cada uma, com o intuito de responder às três perguntas que serviram de base para o projeto.

$\mathrm{Na}$ primeira etapa, que tinha o objetivo de mensurar a sustentabilidade organizacional do Banco A, foi analisada a viabilidade de aplicação e idoneidade de alguns métodos de avaliação da sustentabilidade organizacional presentes na literatura e, posteriormente, realizada a aplicação do método escolhido. Os dados da mensuração foram obtidos por meio de uma pesquisa documental do Banco A.

Avaliou-se os seguintes métodos: "Dow Jones Sustainability Index" (DJSI, 2016); “Global Reporting Initiative" (GRI, 2015); Indicadores Ethos (ETHOS, 2014); Planejamento estratégico para a sustentabilidade empresarial [PEPSE] (Coral et al., 2003); e Método de avaliação dos indicadores de sustentabilidade [M.A.I.S.] (Oliveira, 2002). A Tabela 1 mostra as vantagens e desvantagens de cada método, em relação à sua aplicação para a pesquisa.

O método adotado para a avaliação da sustentabilidade organizacional do Banco A foi o proposto por Oliveira (2002), no qual analisaram quatro dimensões: social, ambiental, econômica e cultural. A relevância do método se apresentou pelos seguintes fatores: alta análise de políticas internas relacionadas à sustentabilidade (Strobel, 2005)²; análise por meio de indicadores, ou seja, análise da existência, implementação e controle de procedimentos, normas, políticas, códigos ou indicadores quantitativos;

${ }^{2}$ Strobel, J.S. 2005. Modelo para mensuração da sustentabilidade corporativa através de indicadores. Dissertação de Mestrado em Engenharia de Produção. Universidade Federal de Santa Catarina, Florianópolis, SC, Brasil. Disponível em: <https://repositorio.ufsc.br/bitstream/ handle/123456789/102809/223696.pdf? sequence=1\&isAllowed=y >. Acesso em: 28 mar. 2017. 
o método apresenta metodologia de cálculo e pontuação; identifica os pontos fortes e fracos, fraquezas e oportunidades da sustentabilidade da organização.

Dentre as desvantagens do modelo, segundo Oliveira (2002), destacam-se: a aplicação do método depende da existência dos indicadores; necessita-se da aplicação do modelo em outras organizações de mesma área, para a consolidação dos critérios; o método não é conclusivo, uma vez que cada região ou tipo de atividade têm peculiaridades que podem ser incorporadas ao método.

Tabela 1. Métodos de avaliação da sustentabilidade: vantagens e desvantagens

\begin{tabular}{|c|c|c|}
\hline Métodos & Vantagens & Desvantagens \\
\hline DJSI (2016) & $\begin{array}{l}\text { - Reconhecido internacionalmente } \\
\text { - Possui indicadores específicos por setor } \\
\text { - Utilizado como modelo para outras metodologias }\end{array}$ & $\begin{array}{l}\text { - Disponibiliza somente um questionário simples } \\
\text { para avaliação } \\
\text { - Voltado ao mercado financeiro para servir de } \\
\text { "benchmarking" para investidores } \\
\text { - A metodologia de cálculo da pontuação não é } \\
\text { informada completamente }\end{array}$ \\
\hline GRI (2015) & $\begin{array}{l}\text { - Reconhecido internacionalmente } \\
\text { - O Banco A utiliza essa metodologia para elaboração de seu } \\
\text { relatório } \\
\text { - Utilizado como modelo para outras metodologias } \\
\text { - Direcionado para "stakeholders" } \\
\text { - Possui indicadores específicos por setor }\end{array}$ & $\begin{array}{l}\text { - Não informa a metodologia de cálculo da } \\
\text { pontuação }\end{array}$ \\
\hline $\begin{array}{l}\text { ETHOS } \\
(2014)\end{array}$ & $\begin{array}{l}\text { - Amplamente reconhecido em território nacional } \\
\text { - Direcionado para "stakeholders" } \\
\text { - Possui indicadores específicos por setor }\end{array}$ & $\begin{array}{l}\text { - Não informa a metodologia de cálculo da } \\
\text { pontuação } \\
\text { - Voltado para avaliar, principalmente, } \\
\text { responsabilidade social empresarial }\end{array}$ \\
\hline $\begin{array}{l}\text { Coral et al. } \\
(2003)\end{array}$ & $\begin{array}{l}\text { - Análise profunda das práticas de sustentabilidade da } \\
\text { organização } \\
\text { - Informa a metodologia de cálculo da pontuação } \\
\text { - Reconhecido nacionalmente }\end{array}$ & $\begin{array}{l}\text { - Não possui indicadores específicos por setor } \\
\text { - Voltado para fornecer um modelo de } \\
\text { planejamento estratégico }\end{array}$ \\
\hline $\begin{array}{l}\text { Oliveira } \\
\text { (2002) }\end{array}$ & $\begin{array}{l}\text { - Análise da sustentabilidade por meio de indicadores } \\
\text { - Informa a metodologia de cálculo da pontuação } \\
\text { - Identificação de pontos fortes e fracos, fraquezas e } \\
\text { oportunidades das práticas de sustentabilidade } \\
\text { - Reconhecido nacionalmente }\end{array}$ & $\begin{array}{l}\text { - Não possui indicadores específicos por setor } \\
\text { - A avaliação depende da existência de indicadores } \\
\text { na organização }\end{array}$ \\
\hline
\end{tabular}

Fonte: Strobel (2005)

A segunda etapa do projeto tinha o objetivo de comparar os marcos do tema sustentabilidade, nacionais/internacionais e do Banco A para verificar as relações existentes entre eles e demonstrar se o banco foi proativo ou reativo na adoção de práticas sustentáveis. Para levantamento dos marcos nacionais/ internacionais foi realizada uma pesquisa bibliográfica, incluindo-se discussões e acordos, leis e decretos ambientais e regulamentações do setor financeiro e, para os marcos do banco, uma pesquisa documental. Após a coleta dos dados, cada marco do banco foi analisado individualmente para verificar as possíveis relações com os marcos nacionais/internacionais.

Por fim, a terceira etapa visou realizar a análise externa da organização para determinar se ela contribuía ou não para o desenvolvimento sustentável da região. Segundo Strobel (2005), o método M.A.I.S., proposto por Oliveira (2002), tem baixa análise externa do ambiente, ou seja, tem pouco indicadores que mensurem o impacto da empresa na sociedade. Assim, fez-se necessário adotarse outra metodologia a fim de obter-se uma gama maior de indicadores que mensurassem qualitativamente os impactos do Banco A na região em que atua. Adotouse então, a metodologia GRI (2008). Justifica-se a sua escolha pela profunda análise externa que faz (Strobel, 2005), além de conter indicadores do setor financeiro e ser usada pelo Banco A para relatar a sustentabilidade praticada.

Como se tratava de uma análise externa, não foi preciso mensurar os indicadores referentes aos aspectos internos da empresa. Mas, os indicadores da metodologia GRI (2008) não possuem classificação quanto à sua externalidade, ou seja, não são classificados como "interno" ou "externo". Assim, fez-se necessário a classificação desses indicadores. Definiram-se então como externos, os indicadores que mensurassem aspectos referentes à comunidade e internos, aspectos referentes à organização. A partir da classificação, realizou-se a análise documental, que serviu de base para a mensuração dos indicadores. Ao fim da mensuração, foi possível determinar os pontos fortes, fracos, riscos e oportunidades de sua influência externa. 


\section{Métodos de mensuração da sustentabilidade}

O modelo de avaliação M.A.I.S. (Oliveira, 2002), utilizado para mensurar a sustentabilidade organizacional do Banco A, possui quatro dimensões: ambiental, econômica, social e cultural. Cada dimensão é constituída por um conjunto de 10 indicadores, num total de 40 indicadores para a avaliação geral. A Tabela 2 mostra as dimensões da sustentabilidade do método proposto por Oliveira (2002) e seus respectivos indicadores. Cada indicador tem sua pontuação baseada em três critérios: a elaboração ou existência de política ou procedimento (E); a implantação do planejado ou do procedimento adotado (I); e o processo de verificação ou controle adotado na busca de oportunidades de melhoria nos processos de gestão $(V)$. E, cada critério, tem a pontuação que varia de 0 a 3.

Tabela 2. Método para análise da sustentabilidade organizacional: dimensões e indicadores

\begin{tabular}{|c|c|c|}
\hline Dimensões & Item & Indicadores de Sustentabilidade \\
\hline \multirow{10}{*}{ Social } & S1 & Geração de emprego e renda \\
\hline & S2 & Ética organizacional \\
\hline & S3 & Participação em entidades de classe e desenvolvimento regional \\
\hline & S4 & Programas de prevenção de acidentes e doenças para os envolvidos \\
\hline & S5 & Capacitação e desenvolvimento de pessoas \\
\hline & S6 & Programas para a melhoria da qualidade de vida \\
\hline & S7 & Projetos sociais \\
\hline & S8 & Sistema de trabalho socialmente aceitos \\
\hline & S9 & Interação com a sociedade \\
\hline & $\mathrm{S} 10$ & Políticas de responsabilidade social e saúde e segurança \\
\hline \multirow{10}{*}{ Ambiental } & A1 & Política de gestão ambiental \\
\hline & $\mathrm{A} 2$ & Avaliação de aspectos e impactos ambientais do negócio \\
\hline & A3 & Preparação para emergências \\
\hline & A4 & Ações corretivas e preventivas \\
\hline & A5 & Avaliação do desempenho global \\
\hline & A6 & Avaliação de riscos \\
\hline & A7 & Avaliação de oportunidades \\
\hline & A8 & Estratégias para desenvolvimento de tecnologias ecologicamente equilibradas \\
\hline & A9 & Análise do ciclo de vida de produtos/serviços \\
\hline & A10 & Controle operacional \\
\hline \multirow{10}{*}{ Econômica } & E1 & Política de qualidade \\
\hline & E2 & Definição de metas e objetivos \\
\hline & E3 & Gestão de processos, produtos e serviços \\
\hline & $\mathrm{E} 4$ & Controle de não conformidades \\
\hline & E5 & Medição e monitoramento de processos, produtos e serviços \\
\hline & E6 & Auditorias e análise crítica \\
\hline & E7 & Gerenciamento de riscos e crises \\
\hline & E8 & Infraestrutura adequada \\
\hline & E9 & Registros e documentação \\
\hline & E10 & Avaliação dos resultados da organização \\
\hline \multirow{10}{*}{ Cultural } & C1 & Incentivo a criatividade e a liderança \\
\hline & $\mathrm{C} 2$ & Geração de cultura organizacional \\
\hline & C3 & Adequação das comunicações internas e externas \\
\hline & $\mathrm{C} 4$ & Comprometimento da organização \\
\hline & $\mathrm{C} 5$ & Avaliação de fornecedores e do mercado \\
\hline & C6 & Melhoria continua \\
\hline & $\mathrm{C} 7$ & Prática do exercício da cidadania organizacional \\
\hline & $\mathrm{C} 8$ & Existência código de conduta organizacional \\
\hline & C9 & Aprendizagem organizacional \\
\hline & $\mathrm{C} 10$ & Imagem da organização \\
\hline
\end{tabular}

Fonte: adaptado de Oliveira (2002)

$\mathrm{Na}$ Tabela 3 estão discriminados os critérios de avaliação, a pontuação para cada um dos critérios e o significado para cada pontuação.

O método de avaliação então, apresentou uma pontuação máxima de 9 pontos para cada indicador, de
90 pontos para cada dimensão, perfazendo um total de 360. A partir das pontuações, a organização pode alcançar três faixas de sustentabilidade, sendo elas: insustentável (0 a 149 pontos); em busca da sustentabilidade (150 a 249 pontos); e sustentável (250 a 360 pontos). 
Tabela 3. Pontuação e seu significado para os critérios do modelo

\begin{tabular}{llc}
\hline & \multicolumn{2}{c}{ Critério - Existência ou Elaboração do Indicador } \\
\hline Pontuação & \multicolumn{1}{c}{ Significado } \\
\hline Zero & Inexistência do indicador \\
Um & Significando que o indicador existe na organização informalmente \\
Dois & Indicando que o indicador existe formalmente \\
Três & O indicador é parte formal da política da organização, praticado e conhecido por todas as partes interessadas. \\
\hline \multicolumn{3}{c}{ Critério - Implantação do Planejamento ou do Procedimento } \\
\hline Pontuação & \multicolumn{1}{c}{ Significado } \\
\hline Zero & O indicador não está implantado \\
Um & O indicador está implantado em 30\% \\
Dois & O indicador está implantado em 70\% \\
Três & O indicador está implantado em sua plenitude \\
\hline Critério - Verificação/Controle Adotado para a Busca de Oportunidade de Melhorias \\
\hline Pontuação & & Significado \\
\hline Zero & O indicador não está implantado \\
Um & O indicador está implantado em 30\% \\
Dois & O indicador está implantado em 70\% \\
Três & O indicador está implantado em sua plenitude \\
\hline
\end{tabular}

Fonte: adaptado de Oliveira (2002)

A metodologia GRI (2008), utilizada para mensurar a contribuição do Banco A para a comunidade, foi composta por 7 dimensões e 100 indicadores, sendo elas: ambiental ("Environmental" - EN) com 30; direitos humanos ("Human Rights" - HR) com 11; econômica ("Economic" - EC) com 9; responsabilidade pelo produto ("Product Responsibility" - PR) com 9; setorial ("Financial Services" - FS) com 16; social ("Labor" - LA) com 15; e sociedade ("Society" - SO) com 10. Desses, 45 foram classificados como externos. A Tabela 4 mostra quais indicadores foram selecionados de cada dimensão.

Tabela 4. Indicadores utilizados na mensuração de impactos na comunidade

\begin{tabular}{ll}
\hline \multicolumn{1}{c}{ Dimensão } & \multicolumn{1}{c}{ Indicadores Externos } \\
\hline Ambiental & EN11 - EN12 - EN14 - EN26 - EN28 \\
Direitos Humanos & HR1 - HR2 - HR4 - HR5 - HR6 - HR7 - HR9 - HR11 \\
Econômica & EC6 - EC7 - EC8 - EC9 \\
Resp. pelo produto & PR1 - PR2 - PR3 - PR4 - PR5 - PR6 - PR7 - PR8 - PR9 \\
Setorial & FS1 - FS2 - FS3 - FS5 - FS6 - FS7 - FS8 - FS10 - FS13 - FS14 - FS15 - FS16 \\
Sociedade & SO1 - SO5 - SO6 - SO7 - SO8 - SO9 - SO10 \\
\hline
\end{tabular}

Fonte: adaptado de GRI (2008)

As duas metodologias apresentadas, GRI (2008) e Oliveira (2002), serviram de base e são complementares uma a outra na análise de sustentabilidade do banco.

\section{Resultados e Discussão}

\section{Mensuração da sustentabilidade organizacional - Método M.A.I.S.}

A Figura 1 apresenta os pontos fortes e fracos, riscos e oportunidades, obtidos da avaliação da sustentabilidade do Banco A, com base nos métodos propostos por Oliveira (2002) e GRI (2008).

Ao longo do texto, foram discutidas as informações que serviram de base para a confecção da matriz SWOT ("Strenghts", "Weaknesses", "Opportunities" e "Threats") do Banco A. A aplicação do método M.A.I.S., juntamente com a análise documental, resultou na mensuração dos indicadores do Banco A, conforme indicado na Tabela 5.

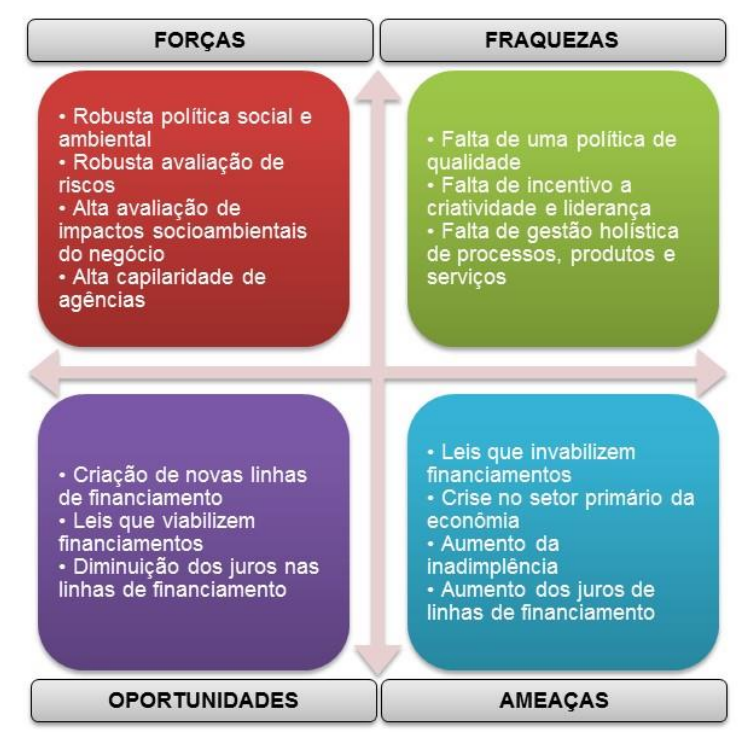

Figura 1. Matriz SWOT Banco A 
Tabela 5. Análise da sustentabilidade do Banco A: pontuação por indicador

\begin{tabular}{|c|c|c|c|c|c|c|}
\hline \multirow{2}{*}{ Dimensões } & \multirow{2}{*}{ Item } & \multirow{2}{*}{ Indicadores de Sustentabilidade } & \multicolumn{3}{|c|}{ Critérios } & \multirow{2}{*}{ Total } \\
\hline & & & $\mathrm{E}$ & I & $\mathrm{V}$ & \\
\hline \multirow{10}{*}{ Social } & S1 & Geração de emprego e renda & 3 & 3 & 3 & 9 \\
\hline & $\mathrm{S} 2$ & Ética organizacional & 3 & 2 & 2 & 7 \\
\hline & S3 & Participação em entidades de classe e desenvolvimento regional & 3 & 3 & 3 & 9 \\
\hline & S4 & Programas de prev. de acidentes e doenças & 3 & 3 & 3 & 9 \\
\hline & S5 & Capacitação e desenvolvimento de pessoas & 3 & 2 & 2 & 7 \\
\hline & S6 & Programas $\mathrm{p} /$ melhoria da qualidade de vida & 3 & 3 & 3 & 9 \\
\hline & S7 & Projetos sociais & 2 & 1 & 2 & 5 \\
\hline & S8 & Sistema de trabalho socialmente aceitos & 3 & 3 & 3 & 9 \\
\hline & S9 & Interação com a sociedade & 3 & 2 & 2 & 7 \\
\hline & $\mathrm{S} 10$ & Políticas de responsabilidade social e saúde e segurança & 3 & 2 & 2 & 7 \\
\hline \multirow{10}{*}{ Ambiental } & A1 & Política de gestão ambiental & 3 & 3 & 3 & 9 \\
\hline & $\mathrm{A} 2$ & Avaliação de aspectos e impactos ambientais do negócio & 3 & 3 & 3 & 9 \\
\hline & A3 & Preparação para emergências & 2 & 3 & 0 & 5 \\
\hline & A4 & Ações corretivas e preventivas & 3 & 2 & 2 & 7 \\
\hline & A5 & Avaliação do desempenho global & 3 & 2 & 2 & 7 \\
\hline & A6 & Avaliação de riscos & 3 & 3 & 3 & 9 \\
\hline & A7 & Avaliação de oportunidades & 2 & 1 & 2 & 5 \\
\hline & A8 & $\begin{array}{l}\text { Estratégias para desenvolvimento de tecnologias ecologicamente } \\
\text { equilibradas }\end{array}$ & 2 & 2 & 2 & 6 \\
\hline & A9 & Análise do ciclo de vida de produtos/serviços & 3 & 3 & 3 & 9 \\
\hline & A10 & Controle operacional & 3 & 3 & 3 & 9 \\
\hline \multirow{10}{*}{ Econômica } & E1 & Política de qualidade & 1 & 0 & 0 & 1 \\
\hline & E2 & Definição de metas e objetivos & 3 & 3 & 3 & 9 \\
\hline & E3 & Gestão de processos, produtos e serviços & 3 & 2 & 2 & 7 \\
\hline & E4 & Controle de não conformidades & 3 & 3 & 3 & 9 \\
\hline & E5 & Medição e monitoramento de processos, produtos e serviços & 3 & 2 & 2 & 7 \\
\hline & E6 & Auditorias e análise crítica & 3 & 3 & 3 & 9 \\
\hline & E7 & Gerenciamento de riscos e crises & 3 & 3 & 3 & 9 \\
\hline & E8 & Infraestrutura adequada & 3 & 2 & 2 & 7 \\
\hline & E9 & Registros e documentação & 3 & 3 & 2 & 8 \\
\hline & E10 & Avaliação dos resultados da organização & 3 & 3 & 3 & 9 \\
\hline \multirow{10}{*}{ Cultural } & C1 & Incentivo a criatividade e a liderança & 2 & 1 & 1 & 4 \\
\hline & $\mathrm{C} 2$ & Geração de cultura organizacional & 3 & 2 & 2 & 7 \\
\hline & $\mathrm{C} 3$ & Adequação comunicações internas/externas & 3 & 2 & 2 & 7 \\
\hline & $\mathrm{C} 4$ & Comprometimento da organização & 3 & 2 & 1 & 6 \\
\hline & $\mathrm{C} 5$ & Avaliação de fornecedores e do mercado & 3 & 3 & 3 & 9 \\
\hline & C6 & Melhoria continua & 1 & 0 & 0 & 1 \\
\hline & $\mathrm{C} 7$ & Prática exercício da cidadania organizacional & 3 & 2 & 1 & 6 \\
\hline & $\mathrm{C} 8$ & Existência código de conduta organizacional & 3 & 2 & 2 & 7 \\
\hline & C9 & Aprendizagem organizacional & 2 & 1 & 1 & 4 \\
\hline & $\mathrm{C} 10$ & Imagem da organização & 3 & 3 & 3 & 9 \\
\hline Total & & & & & & 288 \\
\hline
\end{tabular}

Fonte: adaptado de Oliveira (2002)

Não obstante, a Figura 2 resume a pontuação total de cada dimensão e mostra a localização do Banco A em relação às faixas de sustentabilidade propostas por Oliveira (2002).

Cada dimensão avaliada pode alcançar a pontuação máxima de 90 pontos, com classificações: insustentável, de 0 a 30 pontos; em busca da sustentabilidade, de 31 a 60 pontos; sustentável, de 61 a 90 pontos. A dimensão cultural foi avaliada como "em busca da sustentabilidade", sendo as demais avaliadas como “sustentáveis". A pontuação total do Banco A foi de 288, sendo classificado como sustentável, de acordo com as faixas de sustentabilidade propostas por Oliveira (2002).

Um dos pilares estratégicos da organização foi o desenvolvimento social da região onde atua, segundo relatório de gestão de 2015 (Banco da Amazônia, 2017b). A avaliação da dimensão social, mostrou que o Banco A atua de forma contundente para o desenvolvimento sustentável na Amazônia Legal Brasileira, no que tange aos impactos sociais diretos e indiretos exercidos por ele.

Dentre suas ações, destacam-se positivamente: a geração de emprego e renda local, onde o banco 
tem políticas que incentivam a contratação de empregados e fornecedores locais; as relações de trabalho e o comprometimento com o bem estar social dos empregados; e investimento na capacitação e desenvolvimento de pessoas.

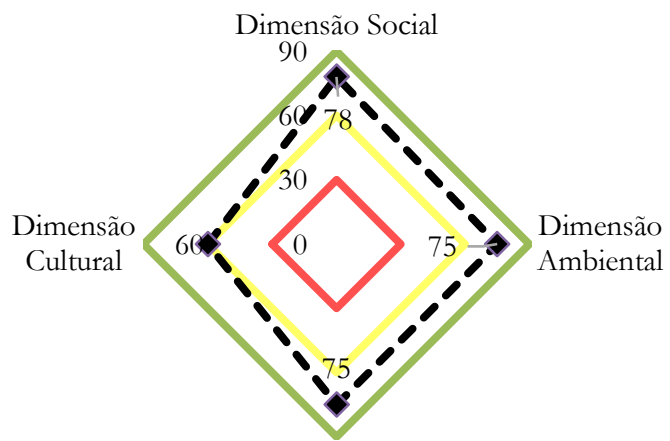

Dimensão Econômica

Figura 2. Localização do Banco A segundo as dimensões de sustentabilidade do método M.A.I.S.

Fonte: adaptado de Oliveira (2002)

Uma das ações que necessitam ser melhoradas e ampliadas foram os projetos sociais desenvolvidos pelo banco, o qual, de acordo com o relatório de sustentabilidade do ano de 2015 (Banco da Amazônia, 2017a), possuía 124 agências e 3195 empregados, mas a maioria dos programas sociais abrangiam somente a matriz. Assim, foi necessário ter maior amplitude desses programas, e outro ponto de melhoria foi o Banco A adotar ações coordenadas e não pontuais para engajar a comunidade com o tema desenvolvimento sustentável.

Outro pilar estratégico do Banco A foi o desenvolvimento sustentável ambiental da Amazônia Legal Brasileira, que assim como a dimensão social, o banco busca o aprimoramento e desenvolvimento na região. Apesar de não ser o ator principal da modificação do bioma da Amazônia, foi corresponsável pelos impactos gerados. $\mathrm{O}$ entendimento da corresponsabilidade está em sua estratégia, políticas e ações que visam, principalmente, mitigar impactos negativos.

Os aspectos que se destacaram em busca do desenvolvimento sustentável ambiental foram: forte política ambiental, que estabelece princípios, diretrizes e estratégias; divulgação do compromisso e posicionamento com a dimensão ambiental; avaliação de riscos e impactos ambientais; e forte controle operacional, através de fiscalizações, consultas de informações nos órgãos competentes e verificação da documentação apresentada pelo financiado. Além disso, também financia projetos de pesquisa e desenvolvimento com recursos próprios nas áreas ambiental, tecnológica, econômica e social. No que tange ao ponto de melhoria que deve ser implementado pelo banco, este não tem uma avaliação satisfatória de possíveis pontos de mitigação do impacto ambiental exercido pelo banco, apesar de ter uma robusta avaliação de riscos.

O macro objetivo estratégico do Banco A, segundo relatório de gestão do ano de 2015 (Banco da Amazônia, 2017b), foi atingir a sustentabilidade econômicofinanceira. Através da mensuração dos indicadores, podese observar que o banco alcançou seu objetivo. Apesar disso, essa dimensão teve pontuação inferior à dimensão social e igual à dimensão ambiental. Analisando os indicadores da organização, percebeu que não há política de qualidade, motivo pelo qual o banco não alcançou uma nota maior. A falta dessa política de qualidade impactou diretamente em outros indicadores que se referem à gestão, análise, medição e ao monitoramento de processos. O Banco A não conseguiu gerir de forma holística seus processos, produtos e serviços, mas possui política de conformidade, que exerceu parte das funções que uma robusta gestão da qualidade exerceria.

No mais, o banco foi bem estruturado na definição e execução de metas e objetivos, além de mensurar, controlar e avaliar, de forma sistemática, os resultados econômicos e os riscos a que a organização está submetida. Não obstante, realizou análises críticas de seus produtos e serviços e auditorias internas e externas para avaliar se a organização está cumprindo corretamente os planos traçados em sua estratégia.

$\mathrm{Na}$ dimensão cultural, foi a que menos o Banco A pontuou, sendo considerada em busca da sustentabilidade. Mais uma vez, verificou-se o impacto da falta de uma política de qualidade. Apesar de, o Banco A mensurar e avaliar a sustentabilidade, ele não pratica formalmente a melhoria contínua da organização. Não há referência de nenhuma ferramenta ou procedimento que formalize a melhoria contínua como um processo sistemático. Além disso não há, de forma objetiva e clara para todos os "stakeholders", indicadores referentes à aprendizagem organizacional. Também, o banco não tem uma política, norma ou procedimento explícito e formal indicando incentivos à criatividade e liderança.

Para atingir seus objetivos estratégicos, o banco, obrigatoriamente, precisa reforçar sua cultura organizacional, para que o conceito de sustentabilidade esteja intrínseco à organização. Assim, é preciso implementar de forma completa a nova gestão de pessoas que o banco vem desenvolvendo, além de aprimorar as comunicações internas e externas e treinar todos os funcionários, sem exceção, quanto ao código de ética.

\section{Evolução das práticas sustentáveis do Banco A}

A segunda etapa da pesquisa, consistia em responder se a evolução das práticas do banco, voltadas para o desenvolvimento sustentável, ocorreram junto com o amadurecimento do tema sustentabilidade ou por 
obrigatoriedade de implantação dessas práticas. É importante salientar, que essa análise não demonstra a aplicação ou efetividade da ação sustentável empreendida pelo Banco A e sim, somente se foi empreendida uma ação ou não. Foram analisados 11 marcos do Banco A.

O primeiro marco de ações sustentáveis adotadas pelo Banco A foi a criação do Fundo Constitucional de Financiamento do Norte [FNO], que foi instituído pela Constituição Federal de 1988, no artigo 159, inciso $\mathrm{I}$, alínea c, e posteriormente regulamentado pela Lei $\mathrm{n}$. 7.827, de 27 de setembro de 1989, e pela Lei n. 9.126, de 10 de novembro de 1995 (SUDAM, 2017).

A criação do fundo tinha como objetivo contribuir para o desenvolvimento econômico e social da região Norte, através de programas de financiamento aos setores produtivos privados. O FNO caracterizou por ser a principal fonte de recursos financeiros estáveis para crédito de fomento, orientado à atender atividades produtivas de baixo impacto ambiental, com o intuito de promover o desenvolvimento sustentável da Região Norte (SUDAM, 2017). Coube ao Banco A ser o gestor do FNO. Desta forma, pode-se afirmar que esse primeiro passo, que foi anterior ao RIO-92 (MMA, 2012) e dois anos depois do Relatório de "Brundtland" (CMMAD, 1998), ou seja, foi uma ação proativa com o objetivo de buscar a sustentabilidade.

O segundo marco refere-se à adesão do Banco A ao Protocolo Verde e à criação da linha de financiamento FNO-Pronaf, que se deu no ano de 1995. O Protocolo Verde surgiu depois da evolução de discussões sobre o tema sustentabilidade. Após a discussão do tema na Rio-92, o Programa das Nações Unidas para o Ambiente [Unep] firmou parceria com bancos, resultando na criação do grupo denominado "Iniciativa Financeira" (Unep-FI) e no ano 1992, foi firmada a Declaração Internacional dos Bancos sobre Meio Ambiente e Desenvolvimento Sustentável (Banco Central do Brasil, 2007). Após essas discussões e acordos, o governo brasileiro criou o Protocolo Verde com o objetivo da incorporação da variável ambiental na gestão e concessão de crédito, tentando diminuir a quantidade de projetos contemplados prejudiciais ao meio ambiente (Braga e Moura, 2015).

Pode-se perceber que a atuação do governo federal e a adesão do Banco A foram proativos, uma vez que acompanharam as discussões ambientais internacionais, sendo o Protocolo Verde pioneiro na América Latina (Braga e Moura, 2015). No mesmo ano, foi criado a linha de crédito FNO-Pronaf, através da Resolução n. 2.191 de 24 de agosto de 1995. Segundo o Banco Central do Brasil (2015), o Pronaf tem o objetivo de estimular a geração de renda e melhorar o uso da mão de obra familiar, através do financiamento de atividades e serviços rurais agropecuários e não agropecuários. É importante salientar, que o Banco A é uma organização, em sua maioria acionária, estatal. Desta forma, algumas ações do banco são indissociáveis do Governo Federal. Neste caso, a resolução do Banco Central pode ser considerada uma ação do banco, uma vez que o Banco A não poderia criar uma linha de crédito sem a aprovação governamental. Assim, a criação do FNO-Pronaf pode ser considerada uma ação proativa, pois o intuito foi promover o desenvolvimento social da região.

O terceiro marco se deu no ano de 2014 com a criação do Projeto Estratégico Excelência por Natureza. Segundo Cintra (2006), os fundos constitucionais de financiamento foram um dos principais instrumentos de fomento regional. Os recursos desses fundos, apesar de terem como prioridade empréstimos a micros e pequenos produtores rurais e micros e pequenas empresas industriais, acabaram sendo direcionados para municípios mais desenvolvidos. Desta forma, terminaram reforçando a tendência de concentração de investimentos (Cintra, 2006). Além disso, a capacidade deles em configurarse como instrumento de política regional foi limitada, embora tenham elevada importância. Não obstante, o Estado em parceria com agentes privados, por meio de uma política de desenvolvimento regional, foi incapaz de viabilizar cadeias produtivas integradas, restando, como instrumento de desenvolvimento, o financiamento microeconômico aleatório, o qual tem pouca capacidade de juntar interesses entre Estado, mercado e sociedade regional (Cintra, 2006).

Nessa problemática, o Banco A, como indutor do desenvolvimento regional, passou a implementar estratégias de desenvolvimento socioeconômico e também programas e ações com o compromisso de promover a inclusão social. Surge então o Plano Estratégico Excelência por Natureza que tem três pilares: Projeto Excelência Humana, que visa à capacitação e o desenvolvimento das pessoas; Projeto Excelência Tecnológica, para atualizar a plataforma tecnológica e prover maior segurança e agilidade nas transações eletrônicas; Excelência em Processos, cujo objetivo foi racionalizar e reestruturar processos.

Além disso, tem quatro eixos prioritários, segundo Cintra (2006): criação da Rede Telemática de Gestão Compartilhada de relacionamentos, com o objetivo de desenvolver sustentavelmente a Amazônia; revisão e implementação dos processos de crédito, risco, atendimento, cursos e tesouraria, para permitir o crescimento do banco; variável ambiental inclusa como negócio, além de elaboração de políticas de desenvolvimento sustentável; criação do Projeto Desenvolve Amazônia, com o objetivo de realizar encontros técnicos de planejamento, com agentes públicos e privados, visando à aplicação dos recursos nos nove Estados da Amazônia Legal. 
O Banco A teve uma postura proativa em relação à evolução da temática sustentabilidade, uma vez que seguiu as discussões internacionais como o Pacto Global e a Cúpula do Milênio, atendendo também à Lei n. 9.605, de 12 de fevereiro de 1998.

O quarto marco foi a criação dos programas Amazônia Recicla, Fornecedor Verde, Amazônia Otimiza e a Nova Política Socioambiental no Crédito, no ano de 2006. A Nova Política Socioambiental foi criada com o objetivo de mudar a postura de negociação, busca de novos clientes e oportunidades de negócios socioambientais sustentáveis. Essa política possibilitava a orientação de clientes, alocação de crédito dentro de critérios da sustentabilidade e divulgação de efeitos de demonstração e de indução de novas operações. A política começou a ser praticada e implementada na concessão de crédito, em 2007, por meio da linha de financiamento FNOAmazônia Sustentável, que foi proposta pelo Banco A e aprovada pelo Ministério da Integração Nacional.

Com a implantação da Nova Política Socioambiental no crédito, o Banco A criou os Programas Amazônia Recicla, Fornecedor Verde e Amazônia Otimiza. No ano de 2006 o Governo Federal publicou o Decreto n. 5.940 de 25 de outubro de 2006, que implementou a coleta seletiva solidária nos prédios de administração pública federal direta e indireta. Os resíduos foram destinados para associações de catadores de materiais recicláveis. No final do ano de 2005, o Banco A realizou ações isoladas de coleta seletiva. Mas, só após o decreto, foi idealizado o programa Amazônia Recicla. Desta forma, o banco passou a ter uma gestão mais abrangente de coleta seletiva. Assim, o Banco A foi reativo na implementação de coleta seletiva, uma vez que foi preciso um decreto para regulamentar as suas ações.

Os programas Fornecedor Verde e Amazônia Otimiza tinham o intuito de estabelecer regras claras para o relacionamento e contratação de fornecedores, e racionar gastos com recursos naturais e administrativos para reduzir desperdícios. Então, observou que a criação da Nova Política Socioambiental no crédito, juntamente com esses dois programas, e a proposição do FNOAmazônia Sustentável, por parte do Banco A, foi uma ação proativa, com o intuito de desenvolvimento sustentável da região.

O quinto marco foi a criação da linha de financiamento FNO-Amazônia Sustentável no ano de 2007. Essa linha de financiamento foi proposta pelo Banco A e aprovada no Ministério da Integração Nacional. Foi criada com vistas ao alinhamento às estratégias do banco de atuar focando do tradicional para o sustentável e do produto para o cliente, sendo abrangente e flexível, e veio substituir outros programas até então vigentes, mas mantendo as bases operacionais legais. Desta forma, a proposição dessa nova linha de financiamento que objetivava atender a população de forma mais sustentável, pode ser considerada uma ação proativa em busca da sustentabilidade.

O sexto marco foi a adesão do Banco A ao Protocolo de Intenções pela Responsabilidade Social e a criação do programa FNO-Biodiversidade. O protocolo de intenções pela responsabilidade socioambiental foi a atualização dos compromissos firmados no Protocolo Verde do ano de 1995, com o objetivo de adaptar os bancos públicos a realidade ambiental brasileira e definir premissas mais claras e objetivas para incorporação da variável ambiental aos negócios (Braga e Moura, 2015; MMA, 2008). Essa versão era mais objetiva em relação à anterior, baseado em diretrizes ante à compromissos da versão do ano de 1995, o que fortaleceu o compromisso com a variável ambiental (Braga e Moura, 2015).

Essa atualização associou-se ao processo de regulação das questões ambientais, através da Resolução n. 3.545 de 29 de fevereiro de 2008, editada pelo Conselho Monetário Nacional, que estabelecia a exigência de documentação comprobatória de regularidade ambiental para fins de financiamento agropecuário no Bioma Amazônia.

O Banco A incorporou a variável ambiental mais profundamente na organização por meio do planejamento estratégico "Excelência por Natureza", e exigiu a documentação comprobatória de regularidade ambiental para financiamentos.

Pode-se então concluir que essas definições foram importantes para o setor bancário e além disso, que o Banco A vinha numa vertente sustentável, demonstrando interesse em criar mecanismos e políticas voltadas para o tema. Isso então caracteriza uma ação proativa do banco, mesmo que fosse necessário fazer algumas mudanças devido à Resolução n. 3.545 de 29 de fevereiro de 2008 (Banco Central do Brasil, 2008).

Em novembro de 2008, foi criado, o FNOBiodiversidade, visando a atender às iniciativas do Governo Federal voltadas para o combate ao avanço do desmatamento na Amazônia, mediante a Medida Provisória n. 432, de 27 de junho de 2008, atualmente, Lei n. 11.775, de 17 de setembro de 2008, que trata da regularização e recuperação de áreas de reserva legal degradadas, a partir do incentivo creditício com bases e condições diferenciadas. Então diante do contexto, o Banco A respondeu reativamente, pois não criou antes, programas que atendessem essas questões relativas ao desmatamento.

O sétimo marco foi a adesão do Banco A à Agenda Ambiental na Administração Pública [A3P], no ano de 2009. A A3P foi criada, informalmente, em 1999 com o objetivo de promover e incentivar as instituições públicas no país a adotarem e implantarem ações na área de responsabilidade socioambiental em suas atividades internas e externas. Dois anos depois, em 2001, foi 
oficialmente criado o Programa Agenda Ambiental na Administração Pública (MMA, 2015). Os que aderem ao programa, recebem selos para reconhecer o empenho na implementação da A3P, sendo conferido o selo verde para instituições que fizeram a adesão formal, prata para as que entregaram relatório anual e laranja para as instituições com melhores práticas de sustentabilidade.

O Banco A somente aderiu ao programa no ano de 2009. Apesar de ter aderido à A3P tardiamente, os programas de gestão ambiental internos do banco que fizeram parte para implementar a A3P datam de 2006. Possivelmente, a demora de implantação ocorreu devido à espera de maturidade dos programas internos. De qualquer forma, o Banco A teve um comportamento reativo nesse caso, demorando a responder as discussões nacionais.

O oitavo marco foi a construção da Agenda 21 do Banco A, no ano de 2010. A construção da Agenda 21 Brasileira começou após as discussões na RIO-92, e esse processo se deu entre os anos de 1996 até 2002. A partir de 2003, a Agenda 21 Brasileira não somente entrou na fase de implementação assistida pela Comissão de Políticas de Desenvolvimento Sustentável [CPDS], como também foi elevada à condição de Programa do Plano Plurianual nos anos 2004 a 2007.

As ações do Banco A para a implementação de sua Agenda 21, começaram no ano de $2008 \mathrm{com}$ os compromissos firmados junto Ministério do Meio Ambiente com a adesão ao Protocolo de Intenções pela Responsabilidade Socioambiental. O documento formal da Agenda 21 do Banco A e o início de sua implementação se deram em 2010.

Visto que o Brasil se esforçou para a elaboração, implementação e monitoramento de compromissos ambientais e sociais por meio da Agenda 21 desde 1996, o Banco A demorou a responder ao cenário brasileiro. Assim, o banco apresentou um comportamento reativo à situação do país.

O nono marco referiu à adoção de um plano para situação climática extrema, no ano de 2012. O Banco A é uma das organizações associadas ao Comitê de Entidades no Combate à Fome e pela Vida - Comunidade, Organizações e Pessoas [COEP], que reúne 1.100 organizações públicas e privadas para a promoção de iniciativas visando o desenvolvimento humano e social, em especial as realizadas em comunidades de baixa renda de todo o País.

O Banco A assumiu, assim, o compromisso de, no caso de situações de emergência provocadas por mudanças climáticas, colocar à disposição dos que necessitam o portfólio de produtos e serviços que possui, além de outros mecanismos que porventura poderão ser mobilizados. Esse plano tem o objetivo de desenvolver ações de prevenção, preparação, resposta e reconstrução no enfrentamento das catástrofes naturais. A criação desse plano foi uma resposta proativa à crescente discussão e preocupação com as mudanças climáticas.

O décimo marco foi a implantação de um novo modelo de gestão de pessoas, no ano de 2014. Esse novo modelo tinha como objetivo modelar a gestão de recursos humanos de forma a produzir impactos financeiros estratégicos nos resultados do banco. Era baseado na gestão por competência e resultados, com seis áreas foco: remuneração estratégica; estrutura de cargos; planejamento e provimento de pessoal; estrutura de carreiras; treinamento e desenvolvimento; e avaliação de desempenho.

Segundo Fischer e Albuquerque (2001), a gestão por competências era considerada de altíssima relevância no ano de 2003, mas, ainda no ano de 2010, a incorporação desse conceito pelas organizações não era grande. Isso demonstrou, que apesar do conhecimento da gestão por competências por parte das empresas, foi algo relativamente recente, não estando amplamente difundido nas mesmas.

A gestão por resultados emergiu na administração pública com a criação da Nova Gestão Pública, no final do século XX, início dos anos 2000. Essa gestão foi orientada por processos de avaliação contínua (Nassuno, 2011). A gestão foi evoluindo e amadurecendo ao longo dos anos de aplicação. Dado o contexto, ao adotar um misto de abordagens de gestão pessoas, considerando principalmente a gestão por competência como pilar de sua nova gestão, o Banco A faz um esforço para melhorar a dimensão social do tripé sustentável. Com isso, o banco adotou uma postura proativa.

Por fim, o décimo primeiro marco, no ano de 2015, foi a criação da linha de financiamento FNOABC e a adoção da Nova Política de Responsabilidade Socioambiental [PRSA]. A PRSA substituiu a Política Corporativa pela Sustentabilidade [PCS] de 2011, e atendeu à Resolução n. 4.327, de 25 de abril de 2014 (Banco Central do Brasil, 2014). Não houve mudanças significativas entre as políticas, pois o Banco A incorporava critérios de sustentabilidade socioambiental em todo o seu processo de atuação. Desta forma, o Banco A foi proativo em adotar políticas com o objetivo de melhorar as dimensões social e ambiental.

O Programa para Redução da Emissão de Gases de Efeito Estufa na Agricultura, denominado Programa ABC (Agricultura de Baixo Carbono), foi criado em 2010 pelo Ministério da Agricultura, Pecuária e Abastecimento [Mapa] com o objetivo de financiar práticas adequadas, tecnologias adaptadas e sistemas produtivos eficientes que contribuam, para a diminuição da emissão dos gases causadores de efeito estufa. O Banco A implementou esse programa em 2015. De certa forma, a implementação do Programa ABC pelo Banco 
A não era obrigatória. Mas como o banco tem a missão de desenvolver sustentavelmente a Amazônia, percebese que foi uma ação proativa por parte do banco.

Ao total foram empreendidas 15 ações, divididas em 11 marcos, voltadas para o desenvolvimento da sustentabilidade.
Dessas, 11 foram proativas e 4 reativas (Tabela 6).

De forma geral, o Banco A adotou ações para o desenvolvimento sustentável de acordo com o amadurecimento da organização e não por obrigatoriedade de implantação dessas ações.

Tabela 6. Marcos da evolução da sustentabilidade do Banco A

\begin{tabular}{|c|c|c|c|}
\hline Marco & Ano & Ação & Tipo \\
\hline $1^{\circ}$ & 1989 & Criação do Fundo Constitucional de Financiamento do Norte [FNO] & Proativa \\
\hline o & 1005 & Adesão ao Protocolo Verde & Proativa \\
\hline $2^{\circ}$ & 1995 & Criação do FNO-Pronaf & Proativa \\
\hline $3^{\circ}$ & 2004 & Projeto Estratégico Excelência por Natureza & Proativa \\
\hline $4^{\circ}$ & 2006 & Programa Amazônia Recicla & Reativa \\
\hline $4^{\circ}$ & 2006 & Nova política Socioambiental no Crédito/ Fornecedor Verde/ Amazônia otimiza & Proativa \\
\hline $5^{\circ}$ & 2007 & Criação do FNO-Amazônia Sustentável & Proativa \\
\hline $6^{\circ}$ & 2008 & $\begin{array}{l}\text { Adesão ao protocolo de intenções pela responsabilidade socioambiental } \\
\text { Criação do FNO-biodiversidade }\end{array}$ & $\begin{array}{l}\text { Proativa } \\
\text { Reativa }\end{array}$ \\
\hline $7^{\circ}$ & 2009 & Adesão à agenda ambiental na administração pública [A3P] & Reativa \\
\hline $8^{\circ}$ & 2010 & Agenda $21-$ Banco A & Reativa \\
\hline $9^{\circ}$ & 2012 & Plano para situação climática extrema & Proativa \\
\hline $10^{\circ}$ & 2014 & Novo modelo de gestão de pessoas & Proativa \\
\hline $11^{\mathrm{o}}$ & 2015 & $\begin{array}{l}\text { Criação FNO-ABC } \\
\text { Nova Política de Responsabilidade Socioambiental [PRSA] }\end{array}$ & $\begin{array}{l}\text { Proativa } \\
\text { Proativa }\end{array}$ \\
\hline Total & & $\begin{array}{c}\text { Proativa } \\
\text { Reativa }\end{array}$ & $\begin{array}{c}11 \\
4\end{array}$ \\
\hline
\end{tabular}

\section{Contribuições do Banco A para o Desenvolvimento} da Região onde Atua

A fim de verificar se o Banco A contribui para o desenvolvimento sustentável regional foram selecionados 45 indicadores da metodologia GRI (2008) de acordo com o exposto na seção "Materiais e Métodos". Desses
45 indicadores, 27 foram mensurados integralmente, ou seja, obteve-se todos os dados necessários para a mensuração. Os outros 7 foram mensurados parcialmente, o que significa que apenas parte dos dados para medir o indicador foram encontrados, e 11 não foram mensurados por falta de dados (Figura 3).

\section{MAPA DE INDICADORES}

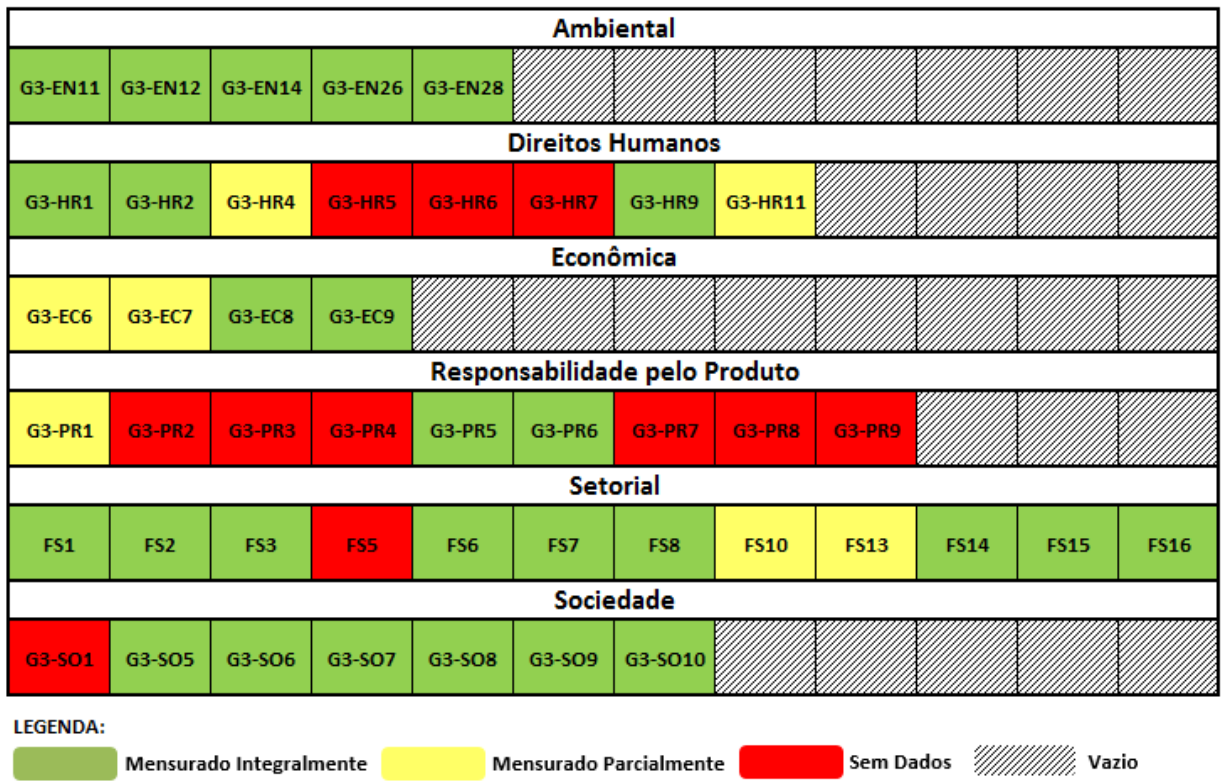

Figura 3. Mapa de indicadores

Fonte: adaptado de Banco da Amazônia (2017a, b) e GRI (2008) 
$\mathrm{Na}$ dimensão ambiental, no que tange ao aspecto "biodiversidade" (GRI, 2008), o Banco, conforme relatório de sustentabilidade e relatório de gestão de 2015 (Banco da Amazônia, 2017a, b), não possuiu propriedades (próprias ou arrendadas), ou realizou atividades, dentro de áreas protegidas ou com alto índice de biodiversidade. Então o banco não impactou diretamente na biodiversidade da região. Em relação aos possíveis impactos indiretos causados por seus produtos e serviços, o Banco não financiou empreendimentos rurais ou não rurais que estejam em áreas protegidas. Além disso, não permitiu que sejam utilizadas, de forma ilegal e não sustentável, as áreas de alto índice de biodiversidade, estando em conformidade com leis e regulamentos ambientais.

O banco contou ainda, com estratégias e programas para a gestão da biodiversidade. Em sua missão, incorpora o conceito de desenvolvimento sustentável, com o objetivo de ser reconhecido por suas ações na região em que atua. O FNO-Biodiversidade é um programa específico para recuperar e regularizar áreas de reserva legal e áreas de preservação permanente degradadas/ alteradas. O FNO-Amazônia Sustentável, no segmento industrial, viabiliza empreendimentos de transformação de produtos florestais madeireiros e não madeireiros.

Em relação aos aspectos "conformidade", "controle acionário ativo" e "energia" (GRI, 2008), o banco, nos anos 2014 e 2015, conforme relatórios de sustentabilidade dos mesmos anos (Banco da Amazônia, 2017a), não apresentou nenhuma multa significativa ou sansões não monetárias da não conformidade com leis e regulamentos ambientais. Além disso, de acordo com o relatório de gestão do FNO do ano de 2015 (Banco da Amazônia, 2017b), o banco apresentou um índice de interação socioambiental de $37 \%$, ou seja, $37 \%$ dos clientes do banco necessitam comprovar sua regularidade socioambiental. $\mathrm{O}$ índice baixou devido à grande quantidade de financiamentos a agricultores familiares e microempreendedores, que não necessitaram preencher uma ferramenta de análise socioambiental aplicada pelo Banco A, mas ainda precisaram comprovar sua regularidade ambiental e social. No que tange a iniciativas para fornecer produtos com baixo consumo de energia, o banco criou o programa Amazônia Otimiza, no ano de 2006, que mensurou o consumo de recursos naturais da organização, segundo relatório de sustentabilidade de 2015 do Banco A (Banco da Amazônia, 2017a).

Por fim, em relação aos aspectos "portfólio de produtos" e "produtos e serviços" (GRI, 2008), o banco contou com uma política específica que incorporou componentes ambientais denominada Política de Responsabilidade Socioambiental [PRSA]. O Banco A demonstrou seu compromisso em relação aos seus produtos, adotando procedimentos para a avaliação e triagem de riscos socioambientais e processo de monitoramento no cumprimento das exigências, como fiscalizações in loco e consulta às informações disponibilizadas pelos órgãos competentes, conforme observado no relatório de sustentabilidade do ano de 2015 (Banco da Amazônia, 2017a). Ainda, os produtos como FNO-ABC, FNO-Biodiversidade e FNOAmazônia sustentável, geraram um alto valor monetário com benefício ambiental. De acordo com o relatório de sustentabilidade do ano de 2015 (Banco da Amazônia, 2017a), o banco financiou R\$99,7 milhões para projetos de reflorestamento e recuperação de áreas degradadas por meio destes dois programas.

Em suma, o banco apresentou comprometimento com a dimensão ambiental, apesar de não criar ferramentas que possibilitem a interação entre a organização e a comunidade para a adoção de práticas ambientais mais sustentáveis.

Quanto à dimensão econômica, apesar da metodologia apresentar poucos indicadores externos nessa dimensão, estes foram suficientes para inferir sua contribuição para o desenvolvimento da região onde atua. Os indicadores abrangeram vários aspectos, dentre eles: portfólio da empresa discriminado por região, porte e setor; políticas, práticas e proporção de gastos com fornecedores locais; procedimentos para a contratação de mão de obra local; impacto de investimentos em infraestrutura e serviços oferecidos, para benefício público; e identificação de impactos econômicos indiretos gerados.

Por meio das linhas de financiamento, o banco gera impactos econômicos indiretos significativos. Para mensurar esses impactos, ele se utilizou da metodologia insumo-produto. Em 2015, de acordo com o relatório de sustentabilidade do mesmo ano (Banco da Amazônia, 2017a), a estimativa para a concessão de crédito pelo FNO, teve o potencial de gerar incremento de $\mathrm{R} \$ 35,4$ bilhões ao valor bruto da produção regional [VBP], aumentar em R\$ 18,7 bilhões o Produto Interno Bruto [PIB] da Região Norte, além de criar 643.566 novas oportunidades de trabalho, tanto no campo quanto nas cidades, gerar salários no valor de R \$ 3,8 bilhões e elevar a arrecadação de tributos em $\mathrm{R} \$ 5,2$ bilhões. Além dos impactos indiretos ocasionadas pela concessão de crédito, o banco também apresentou políticas que privilegiam a contratação de fornecedores e colaboradores locais. Conforme relatório de sustentabilidade do ano de 2014 (Banco da Amazônia, 2017a), 98,99\% das admissões corresponderam à mão de obra local. Por fim, o banco investiu em infraestrutura com o intuito de abranger toda a região e fomentar o desenvolvimento econômico e social.

Com os indicadores mensurados, pode-se inferir que o banco contribuiu para o desenvolvimento econômico da região, principalmente por meio da concessão de 
crédito, que possui alta capilaridade, beneficiando até mesmo regiões remotas.

Em relação à dimensão direitos humanos, o Banco A tem a política de contratação de fornecedores denominada "Fornecedor Verde" que exigiu que este esteja em dia com o cumprimento das obrigações trabalhistas e sociais relacionadas aos direitos fundamentais de trabalhadores, crianças e adolescentes. O outro indicador foi referente à violação de direitos de povos indígenas. Neste caso, o banco não violou esses direitos diretamente e nem indiretamente, pois não financiou projetos em reservas indígenas, em conformidade com leis ambientais.

Os indicadores relatados parcialmente se referem ao número de queixas e casos de discriminação referentes aos direitos humanos. Os números de queixas não foram discriminados por tipo, sendo apresentados os dados consolidados. Desta forma, não foi possível verificar qual o número e a porcentagem total de queixas sobre direitos humanos. Em relação aos casos de discriminação, não foi relatado nenhum caso no ano de 2015 , de acordo com o relatório de sustentabilidade do mesmo ano do Banco A (Banco da Amazônia, 2017a).

No que tange aos indicadores não mensurados, o banco não apresentou os dados referentes ao número de operações e fornecedores que foram identificados em que o direito de exercer a liberdade de associação e a negociação coletiva estava sendo violado, com risco significativo de ocorrência de trabalho infantil e forçado e quais as providências tomadas pelo banco.

Por fim, o banco cumpre a observância dos direitos humanos em relação aos seus fornecedores e empresas contratadas. No entanto, não teve uma política holística para tratar do assunto, uma vez que não abordou corretamente os casos de violação desses direitos. Além disso, também não tratou suas reclamações de forma discriminada, não sendo possível identificar quais foram referentes aos direitos humanos.

$\mathrm{Na}$ dimensão sociedade, no que diz respeito às inciativas para melhorar o acesso dos serviços do banco a pessoas desfavorecidas, o banco tem inciativas de inclusão social como, de acordo com relatório de sustentabilidade do ano de 2015 (Banco da Amazônia, 2017a): terminais de autoatendimento com padrões de acessibilidade; centrais telefônicas; e mecanismos externos como rampas de acesso, piso tátil, mobiliário adaptado, entre outros. Além disso, em relação a pontos de acesso em áreas com baixa densidade populacional, o banco tem alta capilaridade, contando com agências e pontos de atendimento em várias microrregiões da Amazônia Legal Brasileira. As operações, produtos e serviços do banco na comunidade, podem ser considerados como impactantes, tanto negativa como positivamente. Para mitigar possíveis impactos negativos, o banco adota o gerenciamento de risco socioambiental, relacionados a sistemas, banco de dados e critérios específicos de análise creditícia para atividades. O banco não possui multas relativas à não conformidade com leis e regulamentos, de acordo com o relatório de sustentabilidade do ano de 2015 (Banco da Amazônia, 2017a).

É importante salientar, a contribuição do banco para a formação de políticas públicas. Como é um banco com maioria de participação acionária do Governo Federal, ele atua alinhado às estratégias do Governo, juntamente e de forma articulada com parceiros institucionais e sociedade civil. Desta forma, busca integrar políticas, planos e programas governamentais, possibilitando geração de oportunidades para a região onde atua.

Por meio de sua atuação como agente de desenvolvimento social da região, de suas políticas, normas, procedimentos, além de programas de financiamento, o Banco A conseguiu abranger vários segmentos da economia e impactar o desenvolvimento social da região. É importante ressaltar, que falta ao banco uma ação coordenada e não pontual para engajar a comunidade com o tema desenvolvimento sustentável.

Em relação à dimensão responsabilidade pelo produto, no aspecto "comunicação de marketing" o banco adotou práticas condizentes com leis e normas para fazer suas ações de marketing. Mas, não indicou se adotou práticas de não conformidade nesta área. Em relação à não conformidade com leis e regulamentos ao fornecimento e uso de produtos e serviços, e à saúde e segurança dos clientes (externos) o Banco A não apresentou dados para mensuração.

Por fim, o banco adotou práticas que medem a satisfação do cliente, que servem de base para a melhoria dos seus produtos e serviços. Com isso, implementou políticas para o justo desenvolvimento da sociedade, além de ter um programa denominado "Educação Financeira", que orienta seus colaboradores a administrarem melhor seus rendimentos e bens, conforme relatório de sustentabilidade do ano de 2015 (Banco da Amazônia, 2017a).

Nesta dimensão, o banco apresentou vários indicadores que não foram mensurados por falta de dados. Esses indicadores se referem, em sua maioria, a casos de não conformidade com regulamentos, leis e códigos voluntários, relacionados: ao marketing, à rotulagem de produtos e aos impactos causados por produtos, serviços na saúde e segurança durante o ciclo de vida, e multas relativas ao fornecimento inadequado de produtos e serviços. Apesar disso, tem ações que buscaram a sustentabilidade dessa dimensão, destacandose: comunicações de marketing (publicidade, promoção e patrocínio) que atendem à legislação; práticas que buscaram a satisfação do cliente; e a iniciativa denominada "Educação Financeira”. 


\section{Conclusão}

O Banco A é considerado sustentável a partir da mensuração organizacional realizada, com maior pontuação na dimensão social, além de boas avaliações nas dimensões ambiental e econômica. As boas avaliações nessas dimensões, ocorrem devido a ações e políticas proativas voltadas para a sustentabilidade e desenvolvimento da região, como a criação dos fundos FNO, FNO-Pronaf, FNO-Amazônia Sustentável, a adoção do Projeto Estratégico Excelência por Natureza, da Nova Política Socioambiental no Crédito e da Nova Política de Responsabilidade Social. Além disso, a análise temporal dessas ações, demonstram que a evolução das práticas sustentáveis adotadas pelo banco ocorre juntamente com o amadurecimento do tema sustentabilidade e não por obrigatoriedade de implantação.

$\mathrm{Na}$ dimensão cultural o Banco A fica aquém das outras dimensões. A falta de uma política de qualidade é a principal causa desse resultado. A ausência de um procedimento ou ferramenta de melhoria contínua e de indicadores referentes à aprendizagem organizacional, são também relevantes. Além disso, o banco pode ir além do panorama geral identificado nessa pesquisa. Uma vez que, alguns fatores como a criação de novas linhas de financiamento, a diminuição da taxa de juros nessas linhas e leis que propiciem a concessão de crédito, auxiliam positivamente na caminhada rumo ao aperfeiçoamento da sustentabilidade. É importante salientar que, fatores tais como crise no setor primário da economia, aumento na inadimplência, aumento de juros para a concessão de crédito e leis que inviabilizem o aumento de financiamentos, podem prejudicar o Banco A no que tange ao desenvolvimento de suas dimensões sustentáveis.

Não obstante, infere-se que a metodologia utilizada neste trabalho, quando aplicada a outros casos similares, poderá levar a bons resultados, fornecendo maior transparência aos "stakeholders" em relação ao posicionamento frente à sustentabilidade da instituição analisada.

\section{Referências}

Banco Central do Brasil [BCB]. 2007. Boletim Responsabilidade Social e Ambiental do Sistema Financeiro. Disponível em: <http://www.bcb.gov.br/pre/boletimrsa/BOLRSA200703. pdf>. Acesso em: 08 maio 2017.

Banco Central do Brasil [BCB]. 2008. Resolução n. 3545, de 29 de fevereiro de 2008. Altera o MCR 2-1 para estabelecer exigência de documentação comprobatória de regularidade ambiental e outras condicionantes, para fins de financiamento agropecuário no Bioma Amazônia. Disponível em: <http://www.bcb. gov.br/pre/normativos/busca/downloadNormativo. asp? arquivo $=/$ Lists $/$ Normativos $/$ Attachments $/ 47956 /$ Res_3545_v1_O.pdf>. Acesso em: 10 maio 2017.
Banco Central do Brasil [BCB]. 2014. Resolução n. 4327, de 25 de abril de 2014. Dispõe sobre as diretrizes que devem ser observadas no estabelecimento e na implementação da Política de Responsabilidade Socioambiental pelas instituições financeiras e demais instituições autorizadas a funcionar pelo Banco Central do

Brasil. Disponível em: <http://www.bcb.gov.br/pre/ normativos/res/2014/pdf/res_4327_v1_O.pdf>. Acesso em: 10 maio 2017.

Banco Central do Brasil [BCB]. 2015. FAQ - Programa Nacional de Fortalecimento da Agricultura Familiar - Pronaf. Disponível em: <https://www.bcb.gov.br/pre/bc_atende/ port/PRONAF.asp>. Acesso em: 08 maio 2017.

Banco da Amazônia. 2017a. Relatórios de Sustentabilidade. Disponível em: <http://www.bancoamazonia.com.br/ index.php?Itemid=666 >. Acesso em: 09 abr. 2017.

Banco da Amazônia. 2017b. Relatórios de Gestão e Relatórios de Gestão do FNO. Disponível em: < http://www. bancoamazonia.com.br/index.php/relatorio-gestao $>$. Acesso em: 09 abr. 2017.

Braga, C.O.S; Moura, A.S.M. 2015. Protocolo Verde: A Realidade Da Sustentabilidade Ambiental Nas Instituições Financeiras No Brasil. In: VII Jornada Internacional de Políticas Públicas, 2015, São Luís. Anais da VII Jornada Internacional de Políticas Públicas.

Brasil. 1988. Constituição da República Federativa do Brasil, de 05 de outubro de 1988. Artigo 159, inciso I, alínea c. Diário Oficial da União, Brasília, 05 out. 1988. Seção 1, p. 1.

Brasil. 1989. Lein. 7827, de 27 de setembro de 1989. Regulamenta o art. 159, inciso I, alínea c, da Constituição Federal, institui o Fundo Constitucional de Financiamento do Norte - FNO, o Fundo Constitucional de Financiamento do Nordeste - FNE e o Fundo Constitucional de Financiamento do CentroOeste - FCO, e dá outras providências. Diário Oficial da União, Brasília, 28 set. 1989. Seção 1, p. 17361.

Brasil. 1995. Lei n. 9126, de 10 de novembro de 1995. Dispõe sobre a aplicação da Taxa de Juros de Longo Prazo - TJLP sobre empréstimos concedidos com recursos dos Fundos Constitucionais de Financiamento das Regiões Norte, Nordeste e Centro-Oeste e dos Fundos de Investimentos do Nordeste e da Amazônia e do Fundo de Recuperação Econômica do Espírito Santo, e com recursos das Operações Oficiais de Crédito, altera dispositivos da Lei n. 7827, de 27 de setembro de 1989, e dá outras providências. Diário Oficial da União, Brasília, 13 nov. 1995. Seção 1, p. 18073.

Brasil. 1995. Resolução n. 2191, de 24 de agosto de 1995. Crédito rural - institui o Programa Nacional de Fortalecimento da Agricultura Familiar (PRONAF). Disponível em: <http:// www.bcb.gov.br/pre/normativos/res/1995/pdf/res_2191_ v3_L.pdf>. Acesso em: 08 maio 2017.

Brasil. 1998. Lei n. 9605, de 12 de fevereiro de 1998. Dispõe sobre as sanções penais e administrativas derivadas de condutas e atividades lesivas ao meio ambiente, e dá outras providências. Diário Oficinal da União, Brasília, 13 fev. 1998. Seção 1, p. 1

Brasil. 2006. Decreto n. 5940, de 25 de outubro de 2006. Institui a separação dos resíduos recicláveis descartados pelos órgãos e entidades da administração pública federal direta e indireta, na fonte geradora, e a sua destinação às associações e cooperativas dos catadores de materiais recicláveis, e dá 
outras providências. Disponível em: <http://www.planalto. gov.br/ccivil_03/_ato2004-2006/2006/decreto/d5940. htm>. Acesso em: 10 maio 2017.

Brasil. 2008. Lei n. 11775, de 17 de setembro de 2008. Institui medidas de estímulo à liquidação ou regularização de dívidas originárias de operações de crédito rural e de crédito fundiário; altera as Leis n. 11322, de 13 de julho de 2006, 8171, de 17 de janeiro de 1991, 11524, de 24 de setembro de 2007, 10186, de 12 de fevereiro de 2001, 7827, de 27 de setembro de 1989, 10177, de 12 de janeiro de 2001, 11718, de 20 de junho de 2008, 8427, de 27 de maio de 1992, 10420, de 10 de abril de 2002, o Decreto-Lei n. 79, de 19 de dezembro de 1966, e a Lei no 10978, de 7 de dezembro de 2004, e dá outras providências. Diário Oficial da União, Brasília, 18 set. 2008. Seção 1, p. 9.

Brasil. 2008. Medida Provisória n. 432, de 27 de maio de 2008. Institui medidas de estímulo à liquidação ou regularização de dívidas originárias de operações de crédito rural e de crédito fundiário, e dá outras providências. Diário Oficial da União, Brasília, 28 maio 2008. Seção 1, p. 2.

Cintra, M.A.M. 2006. Fundos Constitucionais de Financiamento (do Norte, do Nordeste e do Centro-Oeste). In: Centro de Estudos de Conjuntura e Política Econômica. 2006-2007: O Brasil na Era da Globalização: Condicionantes Domésticos e Internacionais ao Desenvolvimento. CECON, Campinas, SP, Brasil.

Comissão Mundial sobre Meio Ambiente e Desenvolvimento [CMMAD]. 1988. Nosso Futuro Comum. 1ed. FGV, Rio de Janeiro, Brasil.

Coral, C.; Rossetto, C. R.; Selig, P. M. 2003. Planejamento Estratégico para a Sustentabilidade Empresarial: Uma Proposta para Convergência das Estratégias Econômicas, Ambientais e Sociais. In: XXVII Encontro da Associação Nacional de Pós-graduação e Pesquisa em Administração, 2003, Atibaia. Anais do XXVII Encontro da Associação Nacional de Pós-graduação e Pesquisa em Administração.

Dow Jones Sustainability Index [DJSI]. 2016. CSA Guide - Robecosam's Corporate Sustainability Assessment Methodology. Disponível em: <http://www.robecosam. $\mathrm{com} / \mathrm{en} / \mathrm{sustainability-insights/about-sustainability/}$ corporate-sustainability-assessment/resource-center.jsp $>$. Acesso em: 28 mar. 2017.

Elkington, J. 1994. Towards the sustainable corporation: winwin-win business strategies for sustainable development. California Management Review 36(2): 90-100.

Elkington, J. 2004. Enter the triple bottom line. p. 1-16. In: Henriques, A.; Richardson, J. The Triple Bottom Line: Does it All Add Up? Assessing the Sustainability of Business and CSR. Earthscan, Sterling, VA, USA.

Fischer, A.L.; Albuquerque, L.G. 2001. Tendências que orientam as decisões dos formadores de opinião em gestão de pessoas no Brasil - RH 2010. Anais do Encontro Nacional da Associação Nacional de Pós-Graduação e Pesquisa em Administração 25.

Gil, A.C. 2008. Métodos e Técnicas de Pesquisa Social. Editora Atlas, São Paulo, SP, Brasil.

Global Reporting Initiative [GRI]. 2008. Diretrizes para Relatório de Sustentabilidade e Suplemento Setorial de Serviços Financeiros. Disponível em: <https://www.
globalreporting.org/resourcelibrary/G3-BrazilianPortuguese-Financial-Services-Sector-Supplement.pdf $>$. Acesso em: 03 maio 2017.

Global Reporting Initiative [GRI]. 2015. Princípios para Relato e Conteúdos Padrão. Disponível em: <https://www. globalreporting.org/resourcelibrary/Brazilian-PortugueseG4-Part-One.pdf>. Acesso em: 28 mar. 2017.

Instituto Ethos [ETHOS]. 2014. Indicadores Ethos para Negócios Sustentáveis e Responsáveis. Disponível em: $<$ http://www3.ethos.org.br/cedoc/indicadores-ethos-paranegocios-sustentaveis-e-responsaveis/\#.WNrACvkrLIU>. Acesso em: 28 mar. 2017.

Krajnc, D.; Glavič, P. 2005. A model for integrated assessment of sustainable development. Resources in Conservation and Recycling 43(2): 189-208.

Ministério do Meio Ambiente [MMA]. 2008. Protocolo de Intenções Pela Responsabilidade Socioambiental. Disponível em: <http://www.mma.gov.br/estruturas/182/_arquivos/ protocoloverde_bancos_pblicos_agosto_2008.pdf > . Acesso em: 10 maio 2017.

Ministério do Meio Ambiente [MMA]. 2012. Agenda 21 Global. Disponível em: <http://www.mma.gov.br/responsabilidadesocioambiental/agenda-21/agenda-21-global>. Acesso em: 08 maio 2017.

Ministério do Meio Ambiente [MMA]. 2015. A História da A3P. Disponível em: < http://www.mma.gov.br/destaques/ item/8852>. Acesso em: 11 maio 2017.

Nassuno, M. 2011. Gestão por resultados do Governo Federal brasileiro: um breve histórico e perspectivas. Revista Segurança, Justiça e Cidadania 5: 139-149.

Romeiro, A.R. 1999. Desenvolvimento sustentável e mudança institucional: notas preliminares. Revista Econômica 1: 75103.

Silva, E.L.; Menezes, E.M. 2005. Metodologia de Pesquisa e Elaboração de Dissertação. 4ed. Universidade Federal de Santa Catarina, Florianópolis, SC, Brasil. Disponível em: $<$ https://projetos.inf.ufsc.br/arquivos/Metodologia_de_ pesquisa_e_elaboracao_de_teses_e_dissertacoes_4ed.pdf $>$. Acesso em: 15 maio 2017.

Silva, M.C. 2011. Crédito bancário e desenvolvimento sustentável nas instituições financeiras brasileiras. Dissertação de Mestrado em Desenvolvimento Sustentável. Universidade de Brasília, Brasília, DF, Brasil. Disponível em: <http:// repositorio.unb.br/bitstream/10482/10092/1/2011_ MarceloCamposSilva.pdf>. Acesso em: 28 mar. 2017.

Superintendência do Desenvolvimento da Amazônia [SUDAM]. 2017. Fundo Constitucional do Norte - FNO. Disponível em: <http://www.sudam.gov.br/index.php/ fno >. Acesso em: 08 maio 2017.

Van Bellen, H.M. 2006. Indicadores de sustentabilidade: uma análise comparativa. Fundação Getúlio Vargas, Rio de Janeiro, RJ, Brasil. 